\title{
Identification of biomarkers measured upon arrival associated with morbidity, mortality, and average daily gain in grain-fed veal calves
}

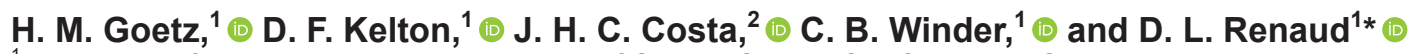 \\ ${ }^{1}$ Department of Population Medicine, University of Guelph, Guelph, ON, Canada N1G 2W1 \\ ${ }^{2}$ Department of Animal and Food Sciences, University of Kentucky, Lexington, KY 40508
}

\begin{abstract}
There is a strong need for management strategies that help reduce the incidence of disease and subsequent antimicrobial use in the veal industry. Biomarkers could serve as useful tools that allow producers to take preventative measures before clinical problems occur. The objective of this prospective cohort study was to identify biomarkers measured upon arrival associated with morbidity, mortality, and average daily gain (ADG) in grain-fed veal calves. Upon arrival at a grain-fed veal facility in Ontario, Canada, calves were weighed and health-scored using a standardized healthscoring system. Several metabolites were measured including creatine kinase (CK), cholesterol, haptoglobin, manganese, serum total protein, iron, cobalt, zinc, selenium, molybdenum, and IgG. Farm personnel treated calves according to their farm protocol and weighed them at $78 \mathrm{~d}$ after arrival. Performance, treatment, and mortality records from the facility were used for analysis. Multivariable Cox proportional hazard models were created to evaluate metabolic biomarkers associated with morbidity and mortality. A mixed linear regression model was created to determine biomarkers associated with ADG. A total of 992 male dairy calves were evaluated at arrival from January to December 2017. Of the calves evaluated, 74 calves $(7.5 \%)$ died and $877(88.4 \%)$ were treated for illness over the 11-wk period under observation. Higher levels of haptoglobin and molybdenum were associated with a greater hazard of morbidity, whereas higher weight upon arrival and higher levels of both CK and IgG were associated with a reduced hazard of morbidity. For mortality, higher weight upon arrival and higher levels of cholesterol and $\operatorname{IgG}$ were associated with a lower hazard of mortality occurring over the 78-d period of observation. Higher weight, cholesterol, copper, CK, iron, and IgG were associated with increased ADG, whereas increased zinc
\end{abstract}

Received April 16, 2020.

Accepted August 15, 2020.

*Corresponding author: renaudd@uoguelph.ca and haptoglobin were negatively associated with ADG. These results demonstrate that certain biomarkers could be used to identify high-risk calves when measured upon arrival at a veal facility. Future research should focus on determining the utility of these biomarkers to selectively target intervention strategies to improve ADG and reduce morbidity and mortality.

Key words: male dairy calf, antimicrobial use, health status, veal industry

\section{INTRODUCTION}

Male dairy calves endure many challenges early in life, including birth, transportation, commingling, and new housing environments (Brscic et al., 2012). As calves experience these challenges during a time when several physiological systems are still developing, they can affect calf health and performance at veal farms (Van de Water et al., 2003; Hulbert and Moisa, 2016). With growing public concern about the consequences of using antimicrobials in farm animals, for both human and animal health, there is a strong need for management strategies that can reduce the incidence of diseases and subsequent antimicrobial use. Of the European animal husbandry systems, veal is among the highest in antimicrobial use (Pardon et al., 2012). While Canadian antimicrobial-use data are not readily available, morbidity levels are often defined by treatment records; therefore, high morbidity documented during veal rearing likely reflects high antimicrobial use in the Canadian veal industry as well. To address the public concern and reduce antimicrobial use, a plausible strategy could be to select calves based on disease risk and selectively target antimicrobial treatment to high-risk calves (Pardon et al., 2015).

It is well understood that sick calves have a lower ADG compared with healthy calves (Bateman et al., 1990; Virtala et al., 1996a; Thompson et al., 2006). The ADG is inherently connected to carcass weight, one of the primary economic outcomes in the veal sector (Pardon et al., 2015). Hence, strategies to identify calves upon arrival to a veal facility that may have decreased 
ADG over the growing period would allow producers to minimize the effect of disease on ADG through applying tailored interventions to maximize profitability and welfare of the animals.

A biomarker is a marker of a biological process or state that can provide information about a current status or future risk of disease in an individual (Pletcher and Pignone, 2011). Biomarkers could serve as useful tools in food animal production for the surveillance of health status, allowing producers to take preventative measures before clinical problems occur. Many potential biomarkers have been evaluated in male dairy calves, including cortisol, lactate, glucose, IgG, haptoglobin, albumin, bilirubin, packed cell volume, selenium, cholesterol, serum amyloid A, and BW upon arrival (Marcato et al., 2018). Currently, the most reliable predictor for future disease in male dairy calves is BW upon arrival; however, this relationship may be confounded by previous illness, feeding and water provision before transport of calves to the veal farm, lower birth weights of calves, or substantial losses during transportation. Therefore, alternative identifiers of high-risk calves that could be measured upon arrival would be advantageous for producers (Knowles et al., 1997; Bernardini, et al., 2012; Marcato et al., 2018). Blood parameters as predictors of future disease that have been identified in published studies include packed cell volume (Paré et al., 1993), lactate (Buczinski et al., 2015), glucose (Montgomery et al., 2009), IgG (Pardon et al., 2015), and haptoglobin (Yun et al., 2014). Previous work has assessed the suitability of a limited number of biomarkers for predicting future disease; however, studying many potential parameters at once provides the opportunity to identify the most reliable biomarker.

The objective of this prospective single cohort study was to identify biomarkers measured upon arrival for association with morbidity, mortality, and ADG in grain-fed veal calves. We hypothesized that a myriad of blood parameters would be associated with morbidity, mortality, and ADG when measured upon arrival to a veal facility. This manuscript is reported following the STROBE-Vet reporting guidelines for observational studies (O'Connor et al., 2016).

\section{MATERIALS AND METHODS}

This prospective single cohort study was conducted from January 2017 to April 2018 at a grain-fed veal facility in southwestern Ontario, Canada. This farm was chosen due to its close proximity to the University of Guelph and its excellent record keeping and adherence to protocols. All calves arriving at this facility were eligible for enrollment in the study. Prior to the onset of the study, approval from the University of Guelph animal care committee was obtained (Animal Use Protocol \# 3695). This study used blood marker data and data that was previously published by Scott et al. (2019).

\section{Animal Housing and Feeding}

The facility had 4 rooms, each with the capacity to house 80 calves. Each room of calves was considered a "lot," which was used as a grouping variable in the analysis. The age of the calves was unknown, but was likely to be between 3 and $7 \mathrm{~d}$ of age. Calves were housed individually for the first $21 \mathrm{~d}$ in stalls with slatted rubber flooring. After the 21-d acclimatization period, the partitions between individual stalls were removed and calves were housed in groups of 5 . Calves were fed a milk replacer twice daily for $49 \mathrm{~d}$ before transitioning to a grain-based diet after weaning. Milk replacer contained decoquinate $(30 \mathrm{mg} / \mathrm{kg})$ and was formulated to contain $26 \% \mathrm{CP}, 17 \%$ fat, $2.4 \%$ Lys, $0.8 \%$ Met, and 1.6\% Thr. Milk replacer was bucket-fed at a daily feeding rate of $520 \mathrm{~g}$ for wk 1 to $2,650 \mathrm{~g}$ for wk 3 , and $900 \mathrm{~g}$ for wk 4 to 5 in a total of 4,5 , and 6 L of solution, respectively. Feedings were split evenly between morning and evening. Weaning of all calves took place over 2 wk by feeding $450 \mathrm{~g}$ of milk replacer once daily in wk 6 and $450 \mathrm{~g}$ once every third feeding in wk 7 . Texturized calf starter $(18 \% \mathrm{CP})$ was offered to calves upon arrival until wk 3 and transitioned to a corn and pellet ration with $2 \%$ straw $(18.1 \% \mathrm{CP})$. Oral antimicrobial (neomycin, NeoMed; Bimeda Inc., Terrace, IL) was provided in the milk in a subset of rooms and varied depending on whether a feed additive trial was ongoing. Administration of the oral antimicrobial was not based on the health status of the arriving calves.

\section{Data Collection}

Upon arrival at the veal facility, all calves were weighed using a Tru-Test digital weigh scale (Mineral Wells, TX). A single graduate student trained by a veterinarian evaluated all calves and recorded the findings using an iPad (Apple, Inc., Cupertino, CA) equipped with the Calf Health Scorer app (University of Wisconsin-Madison, Madison, WI) and Qualtrics (www .qualtrics.com). The Calf Health Scorer app was used to guide the assessment of the respiratory system (nose, eye, ear, cough), fecal consistency, navel inflammation, joint swelling, and rectal temperature as described by Scott et al. (2019). A Qualtrics form was used to record data on clinical dehydration, BCS, and the presence of a sunken flank. The level of dehydration was scored 
based on skin tent retention, eye recession, and attitude. Health score data are described further in Scott et al. (2019). Blood was collected from the jugular vein of each calf using a 20-gauge 1 -inch needle into a $10-\mathrm{mL}$ sterile blood-collection tube without an anticoagulant (BD Vacutainer; Becton, Dickson and Co., Franklin Lakes, NJ). Blood was allowed to clot and then centrifuged at $1,500 \times g$ for $15 \mathrm{~min}$. Serum was separated and stored in 2 separate aliquots at $-20^{\circ} \mathrm{C}$ until analysis at the Animal Health Laboratory (Guelph, ON, Canada) and Saskatoon Colostrum Company (Saskatoon, SK, Canada). At the Animal Health Laboratory, 11 blood parameters were measured, including creatine kinase (CK), cholesterol, haptoglobin, manganese, serum total protein, iron, cobalt, copper, zinc, selenium, and molybdenum. Creatine kinase was determined using the CK assay, a UV test for the quantitative determination of CK for use in Cobas c systems. (Roche, Mississauga, ON, Canada). Cholesterol concentration was determined using the Roche CHOL2 kit (Roche). Haptoglobin concentrations were measured by determining the hemoglobin binding capacity of serum, which was quantified against a standard sample (Skinner et al., 1991). To measure manganese, iron, cobalt, copper, zinc, selenium, and molybdenum, the serum was diluted with a solution (1:20) composed of $1 \% \mathrm{HNO}_{3}, 1 \%$ isopropanol, 0.01\% TritonX-100, and 0.01\% EDTA and run directly by inductively coupled plasma-MS using a Bruker 820-MS ICPMS with a CETAC ASX 520 auto sampler (Omaha, NE). Serum IgG was evaluated by radial immunodiffusion at the Saskatoon Colostrum company as described by Chelack et al. (1993).

\section{Outcome Assessment}

Throughout the 78-d period at this facility, farm personnel identified and treated calves for disease using a protocol created by their veterinarian, and then weighed calves at $78 \mathrm{~d}$ after arrival. In brief, the treatment protocol prescribed that if calves were identified as having 3 consecutive days of watery diarrhea, blood in loose or watery feces, or loose or watery feces in addition to refusing milk for 2 consecutive feedings, calves were treated with a combination of trimethoprim and sulfadoxine (Borgal, $3 \mathrm{~mL} / 45 \mathrm{~kg}$ of BW i.m. once per day for 3 consecutive days, Merck Animal Health, Kirkland, QC, Canada) and meloxicam (Metacam, 2.5 $\mathrm{mL} / 100 \mathrm{~kg}$ of BW s.c. once; Boehringer, Burlington, Canada). All calves with diarrhea also received $2 \mathrm{~L}$ of electrolytes once daily. Farm personnel screened calves for respiratory disease by evaluating nasal and ocular discharge, abnormal respiration rate, and presence of a cough. If calves displayed respiratory abnormalities, personnel measured rectal temperature. Calves with respiratory disease received both florfenicol (Nuflor, 6 $\mathrm{mL} / 45 \mathrm{~kg}$ of BW s.c. once; Merck Animal Health) and meloxicam (Metacam $2.5 \mathrm{~mL} / 100 \mathrm{~kg}$ s.c. once; Boehringer). Treatment and mortality records were collected from the producer at the end of the observation period and used for analysis. Morbidity was defined as a calf that received treatment for signs of respiratory disease or diarrhea during the 78-d period of observation, and mortality was defined as a calf that died during the 78-d period of observation. The ADG was calculated by subtracting the calf's weight at the beginning of the observation period from its final weight at the end of the observation period and dividing by the number of days in the period. Following the 78-d period of observation, the calves were transported to a larger group-housing facility for an additional 20 wk until slaughter. Morbidity, mortality, and ADG data beyond 11 wk were not recorded or included in the analysis because the larger group-housing facility did not keep reliable records.

\section{Sample Size Calculation}

The number of calves to be enrolled in the study was based on a proportion estimation sample size calculation previously completed by Scott et al. (2019). Based on previous work (Pardon et al., 2015; Renaud et al., 2018), it was estimated that calves arriving at the veal facility with a health abnormality would have a morbidity risk of $26 \%$, and those arriving without an abnormality would have a morbidity risk of $17 \%$. Using a $95 \%$ confidence interval and $80 \%$ power, a sample size of 916 was required.

\section{Statistical Analysis}

Data were collated in Microsoft Excel (Microsoft, Redmond, WA) and exported into STATA15 (Stata/IC Version 15.1 for Mac, StataCorp, College Station, TX) for statistical analyses. A causal diagram was created to evaluate the relationship between calf health and the measured variables (Figure 1). Descriptive statistics were generated for all variables in the data set. Calves with missing data were not included in the analysis.

Four explanatory models were created to explore the relationship between the biomarkers and morbidity, mortality, and ADG. Two multivariable Cox proportional hazard models were created to evaluate metabolic biomarkers associated with morbidity and mortality, controlling for lot as a random effect. A third multivariable Cox proportional hazard model was created to evaluate metabolic biomarkers associated with mortality when weight was added to the model. A mixed linear regression model was generated to evaluate factors associated with ADG over the entire period, 
using lot as a random effect. Martingale residuals were plotted against the continuous variables to assess the linearity of each continuous predictor variable offered to Cox proportional hazard models, whereas a lowess smoothing curve was generated to assess the linearity of each continuous predictor variable for the linear regression models. If a variable failed to meet the linearity assumption, the variable was categorized into quartiles. Collinearity among variables was assessed using Pearson correlation coefficients; if $\geq 0.6$, only one variable was retained in the model based on biological plausibility and reliability of the measurement. Univariable models were created to identify predictor variables unconditionally associated with the outcomes using a $P$-value of $<0.2$. Variables with univariate associations were included in a multivariable model through a manual backward stepwise process. Variables were retained in the multivariable model if $P<0.05$ or if the effect of removing the variable resulted in a change of at least $20 \%$ in the coefficient of a significant variable, indicating potential confounding. Two-way interactions were evaluated between variables based on evidence in the literature and retained in the model if significant. Model fit was assessed using the test of proportional hazards for the Cox proportional hazards models. For the mixed linear regression models, homoscedasticity of the best linear unbiased predictions was assessed using standardized residuals. A scatter plot of the standardized residuals was generated and examined for patterns in the data. Normality of the residuals was visually evaluated using quartile normal plots. Evidence of influential observations was identified using standardized residuals plotted against predicted outcomes. Harrell's C concordance statistic was calculated for each model to evaluate their predictive ability (Dohoo et al., 2010).

The Youden Index (Youden, 1950) is a summary measure of the receiver operator characteristic curve. It was used to identify optimal cut points to maximize sensitivity and specificity for continuous predic-

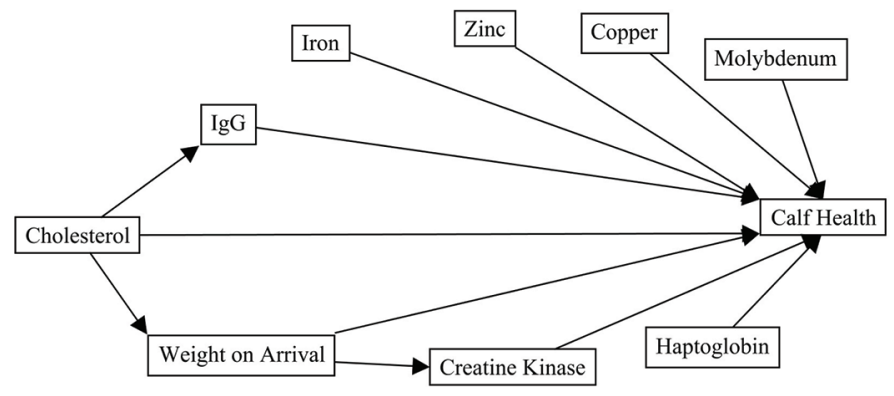

Figure 1. Causal diagram describing the hypothesized relationship of metabolic indicators to calf health measured in 992 calves at arrival to a grain-fed veal facility in southwestern Ontario. tor variables in the Cox proportional hazard models, which were significantly associated with morbidity and mortality.

\section{RESULTS}

\section{Descriptive Statistics}

In 16 lots of calves, 998 calves were evaluated on arrival, and a total of 992 calves were included in the analysis. Six calves were missing blood parameter data. The models were run with and without these 6 calves with no influence on the results; therefore, they were deleted from the analysis. The most calves arrived in the spring (39.7\%), $22.6 \%$ arrived in the summer, $20.6 \%$ arrived in the fall, and the fewest arrived in the winter $(17.2 \%)$. Of the calves evaluated, $149(14.9 \%)$ arrived with at least 1 identifiable health abnormality. In brief, $32 \%$ were clinically dehydrated, $19.9 \%$ had an abnormal navel, $13.5 \%$ had diarrhea, $8 \%$ were dull or depressed, and very few had an abnormal respiratory score upon arrival. For more information on health parameters measured upon arrival, see Scott et al. (2019). The mean weight at arrival $( \pm \mathrm{SD})$ of the calves was 46.96 $\pm 4.84 \mathrm{~kg}$. The overall ADG for the entire observation period was $0.748 \pm 0.444 \mathrm{~kg}$. A total of $872(88.62 \%)$ of calves were treated at least once over the 78 -d period at this facility. The mean time to first treatment was 21.79 $\pm 23.61 \mathrm{~d}$ (range 0-77 d) from day of arrival (Figure 2). Over the 78-d period at this facility, 74 calves $(7.48 \%)$ died (Figure 3). The mean time to mortality was 42.16 \pm 22.33 (range $1-77$ ).

Descriptive statistics for blood parameters and weight measured upon arrival in calves that were treated for

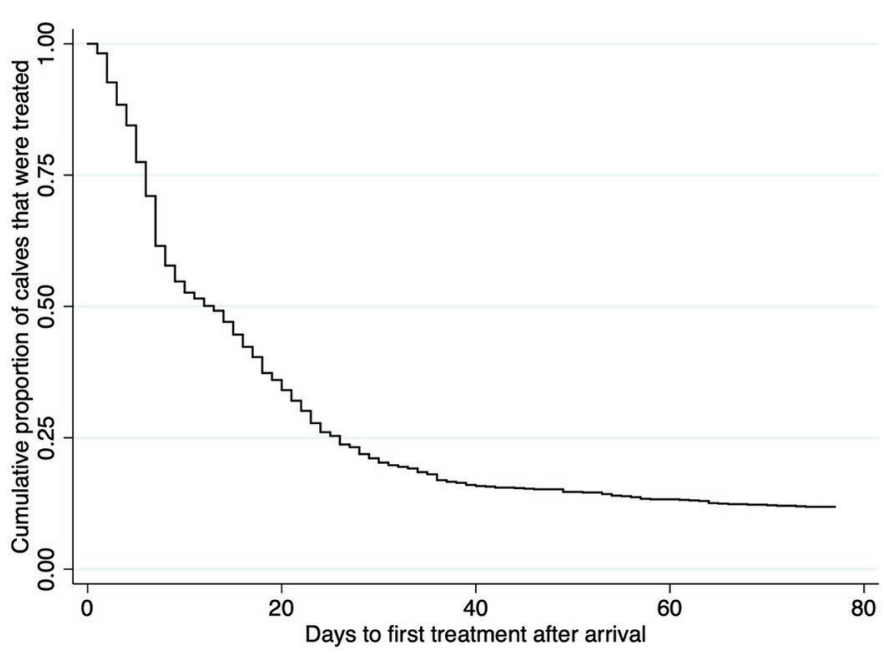

Figure 2. Kaplan-Meier survival estimate: days to first treatment in 992 calves screened on arrival at a grain-fed veal facility. 


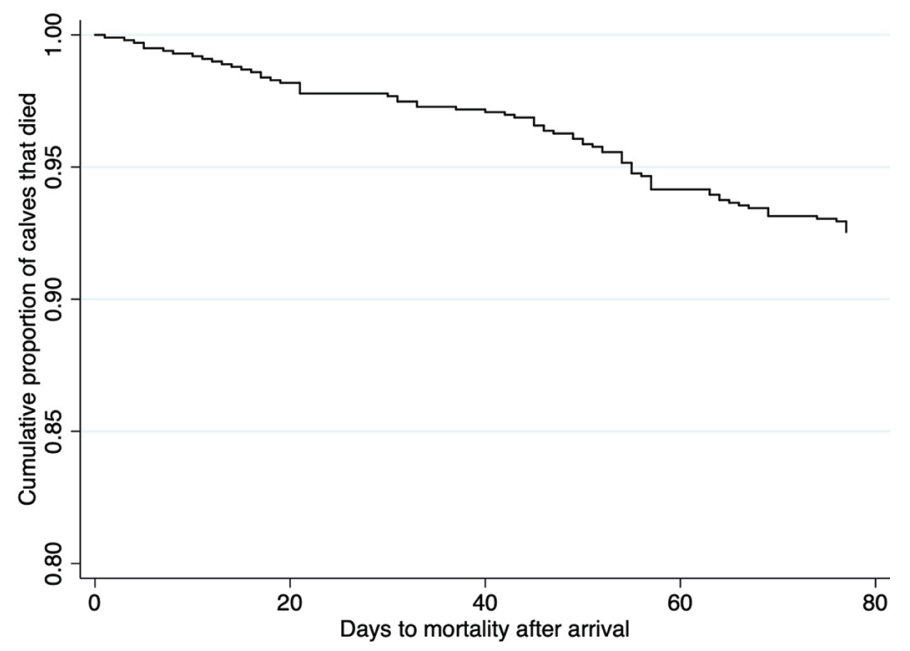

Figure 3. Kaplan-Meier survival estimate: days after arrival that calves died in 992 calves screened on arrival at a grain-fed veal facility.

disease at least once during the observation period compared with calves that were not treated for disease are summarized in Table 1. Descriptive statistics for blood parameters and weight measured upon arrival in calves that died compared with those that did not die in the 78-d period of observation are summarized in Table 2. Disease incidence, mortality, and ADG by lot are summarized in Supplemental Table S1 (https://doi .org/10.3168/jds.2020-18729).

\section{Average Daily Gain Model}

Nine explanatory variables were associated with ADG in univariable analysis: weight at arrival, CK, cholesterol, haptoglobin, iron, copper, zinc, selenium, molybdenum, and IgG. In the final model, weight on arrival, CK, cholesterol, haptoglobin, iron, copper, zinc, and IgG were associated with ADG over the 78-d period (Table 3). No interactions or outliers were identified. Health parameters measured upon arrival using the standardized health-scoring system were not significant in the final model. Calves with higher weight at arrival, CK, cholesterol, iron, copper, and IgG, and calves with lower haptoglobin and zinc had an improved ADG.

\section{Morbidity Model}

In the univariable analysis, level of dehydration, use of group antibiotic treatment, navel score, weight on arrival, IgG, CK, cholesterol, haptoglobin, selenium, and molybdenum were associated with morbidity. In the final multivariable model, weight on arrival, IgG, CK, and haptoglobin were associated with morbidity. Higher weight, IgG, and CK were associated with a

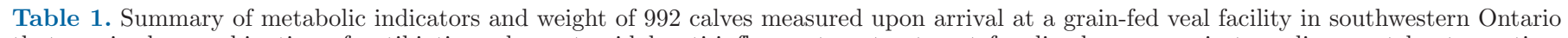
that received a combination of antibiotic and nonsteroidal anti-inflammatory treatment for diarrhea or respiratory disease at least one time compared with calves that were not treated during the 78-d period of observation

\begin{tabular}{|c|c|c|c|c|c|c|}
\hline Variable & Treatment (yes/no) & Mean & $\mathrm{SD}$ & Minimum & Maximum & $P$-value \\
\hline \multirow[t]{2}{*}{ Weight on arrival (kg) } & No & 47.49 & 5.32 & 35.38 & 63.05 & \\
\hline & Yes & 46.88 & 4.78 & 34.02 & 67.59 & $<0.001$ \\
\hline \multirow[t]{2}{*}{ Cholesterol (mmol/L) } & No & 2.02 & 0.65 & 0.91 & 4.23 & \\
\hline & Yes & 1.93 & 0.61 & 0.1 & 4.45 & 0.032 \\
\hline \multirow[t]{2}{*}{ Creatine kinase (U/L) } & No & 168.58 & 96.95 & 27 & 572 & \\
\hline & Yes & 157.51 & 107.91 & 27 & 877 & 0.143 \\
\hline \multirow[t]{2}{*}{ Haptoglobin $(\mathrm{g} / \mathrm{L})$} & No & 0.18 & 0.13 & 0.12 & 1.26 & \\
\hline & Yes & 0.20 & 0.18 & 0.11 & 2.11 & 0.019 \\
\hline \multirow{2}{*}{$\operatorname{IgG}(\mathrm{g} / \mathrm{L})$} & No & 22.29 & 10.04 & 3.7 & 56.8 & \\
\hline & Yes & 20.01 & 9.61 & 0.6 & 61.9 & 0.001 \\
\hline \multirow{2}{*}{ Serum total protein $(\mathrm{g} / \mathrm{dL})$} & No & 5.88 & 0.67 & 4.3 & 8.2 & \\
\hline & Yes & 5.74 & 0.65 & 4 & 8.3 & 0.051 \\
\hline \multirow{2}{*}{ Cobalt (ng/mL) } & No & 26.64 & 8.34 & 11 & 54 & \\
\hline & Yes & 25.79 & 7.29 & 6.2 & 66 & 0.669 \\
\hline \multirow[t]{2}{*}{ Copper $(\mu \mathrm{g} / \mathrm{mL})$} & No & 0.65 & 0.15 & 0.28 & 1.1 & \\
\hline & Yes & 0.66 & 0.17 & 0.25 & 1.5 & 0.848 \\
\hline \multirow[t]{2}{*}{ Iron $(\mu g / m L)$} & No & 3.05 & 1.31 & 0.78 & 7 & \\
\hline & Yes & 3.01 & 1.35 & 0.71 & 14 & 0.879 \\
\hline \multirow[t]{2}{*}{ Manganese (ng/mL) } & No & 2.69 & 1.57 & 1 & 7.6 & \\
\hline & Yes & 2.49 & 1.76 & 1 & 26 & 0.243 \\
\hline \multirow[t]{2}{*}{ Molybdenum (ng/mL) } & No & 12.91 & 11.70 & 2.2 & 100 & \\
\hline & Yes & 16.65 & 19.43 & 1.5 & 280 & 0.003 \\
\hline \multirow[t]{2}{*}{ Selenium $(\mu \mathrm{g} / \mathrm{mL})$} & No & 0.20 & 0.06 & 0.10 & 0.35 & \\
\hline & Yes & 0.21 & 0.07 & 0.04 & 0.61 & 0.065 \\
\hline \multirow{2}{*}{ Zinc $(\mu \mathrm{g} / \mathrm{mL})$} & No & 1.34 & 0.36 & 0.57 & 2.4 & \\
\hline & Yes & 1.30 & 0.36 & 0.32 & 2.6 & 0.254 \\
\hline
\end{tabular}


Table 2. Summary of metabolic indicators and weight of 992 calves measured upon arrival at a grain-fed veal facility in southwestern Ontario that did not die compared with calves that died during the 78-d period of observation

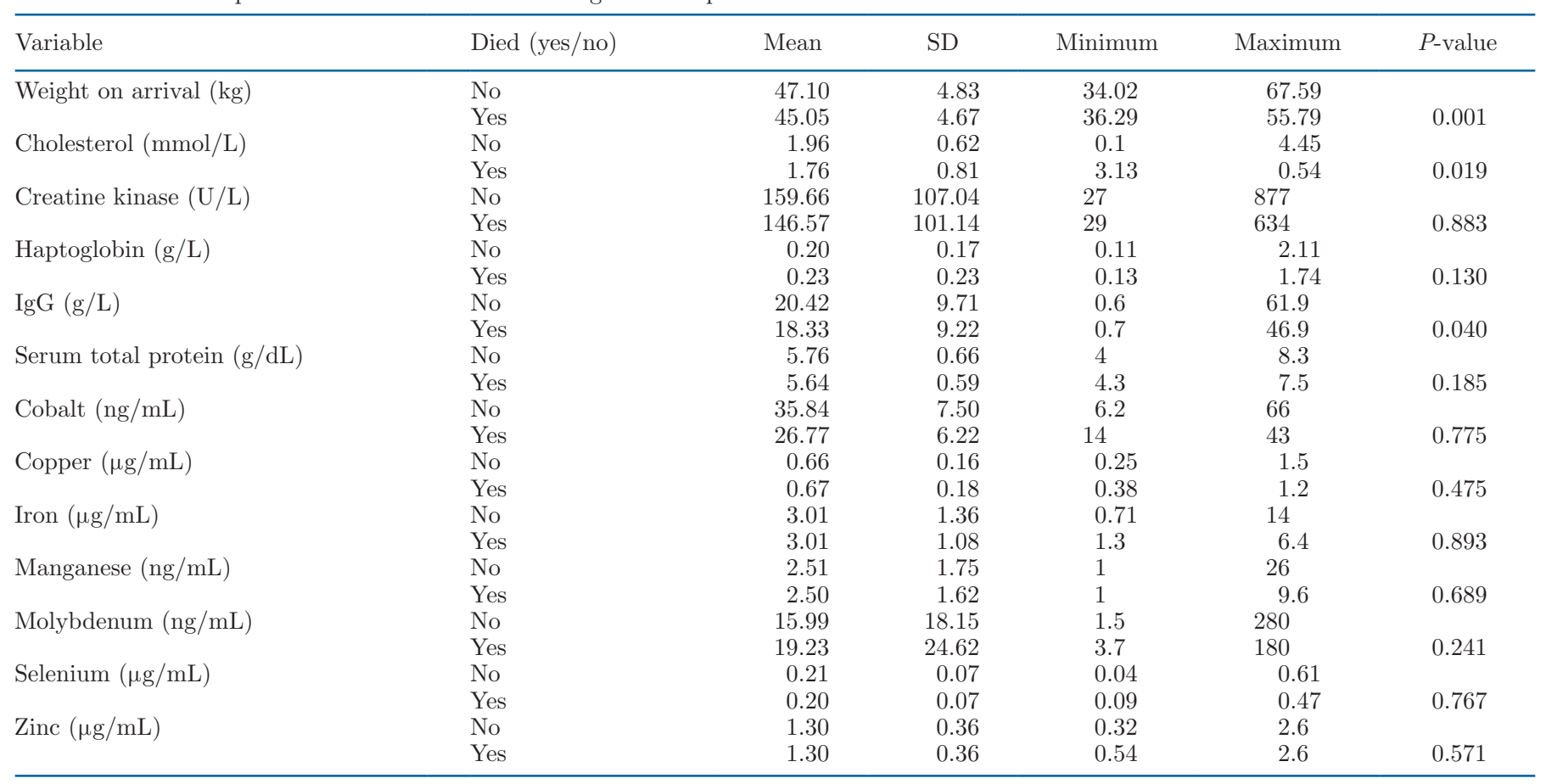

decreased hazard of being treated for disease, whereas calves with higher haptoglobin and molybdenum had an increased hazard of being treated for disease over the 78-d period (Table 4). No interactions were identified in the final model and no outliers were found. The Harrell's C concordance statistic for this model was 0.59 , indicating that the model correctly ordered survival time for pairs of calves $59 \%$ of the time, and suggesting its predictive ability is limited. Cut points were generated using the Youden Index to determine the optimal cut point for IgG, weight, CK, haptoglobin, and molybdenum to predict morbidity (Table 5).

Table 3. Results from a mixed linear regression model identifying metabolic indicators and weight associated with ADG in 992 calves when measured on arrival at a grain-fed veal facility in southwestern Ontario

\begin{tabular}{llcrc}
\hline Variable & Description & $\begin{array}{c}\text { Coefficient } \\
\text { (kg/d) }\end{array}$ & 95\% CI & $P$-value \\
\hline Weight & Every 1 -kg increase & 0.016 & 0.009 to 0.022 & $<0.001$ \\
Cholesterol & Every $1 \mathrm{mmol} / \mathrm{L}$ increase & 0.121 & 0.070 to 0.171 & $<0.001$ \\
Copper & Every $1 \mu \mathrm{g} / \mathrm{mL}$ increase & 0.342 & 0.138 to 0.547 & 0.001 \\
Zinc & Every $1 \mu \mathrm{g} / \mathrm{mL}$ increase & -0.105 & -0.189 to -0.021 & 0.014 \\
Creatine kinase & 27 to $86 \mathrm{U} / \mathrm{L}$ & Referent & & \\
& 87 to $132 \mathrm{U} / \mathrm{L}$ & 0.061 & -0.022 to 0.144 & 0.151 \\
& 134 to $195 \mathrm{U} / \mathrm{L}$ & 0.051 & -0.034 to 0.136 & 0.242 \\
Haptoglobin & 196 to $877 \mathrm{U} / \mathrm{L}$ & 0.160 & 0.073 to 0.246 & $<0.001$ \\
& 0.11 to $0.15 \mathrm{~g} / \mathrm{L}$ & Referent & & \\
& 0.16 to $0.16 \mathrm{~g} / \mathrm{L}$ & -0.020 & -0.113 to 0.072 & 0.66 \\
Iron & 0.17 to $0.19 \mathrm{~g} / \mathrm{L}$ & -0.063 & -0.146 to 0.020 & 0.138 \\
& 0.2 to $2.11 \mathrm{~g} / \mathrm{L}$ & -0.096 & -0.187 to -0.006 & 0.038 \\
& 0.71 to $2.1 \mu \mathrm{g} / \mathrm{mL}$ & Referent & & \\
& 2.2 to $2.8 \mu \mathrm{g} / \mathrm{mL}$ & 0.004 & -0.077 to 0.084 & 0.927 \\
IgG & 2.9 to $3.6 \mu \mathrm{g} / \mathrm{mL}$ & 0.099 & 0.017 to 0.182 & 0.018 \\
& 3.7 to $14 \mu \mathrm{g} / \mathrm{mL}$ & 0.095 & 0.010 to 0.180 & 0.028 \\
& 0.6 to $13.1 \mathrm{~g} / \mathrm{L}$ & Referent & & \\
& 13.2 to $19.4 \mathrm{~g} / \mathrm{L}$ & 0.049 & -0.033 to 0.132 & 0.24 \\
Constant & 19.5 to $26.1 \mathrm{~g} / \mathrm{L}$ & 0.047 & -0.036 to 0.130 & 0.264 \\
& 26.2 to $61.9 \mathrm{~g} / \mathrm{L}$ & 0.132 & 0.049 to 0.216 & 0.002 \\
& & 0.688 & 0.0348 to 1.028 & $<0.001$ \\
\hline
\end{tabular}


Table 4. Results from a Cox proportional hazard model identifying metabolic indicators and weight measured at arrival associated with morbidity during the 78-d period of observation in 992 calves at a grain-fed veal facility in southwestern Ontario

\begin{tabular}{llccc}
\hline Variable & Description & $\begin{array}{c}\text { Hazard } \\
\text { ratio }\end{array}$ & P-value & 95\% CI \\
\hline Weight & Every 1-kg increase & 0.969 & $<0.001$ & 0.956 to 0.983 \\
IgG & Every $1 \mathrm{~g} / \mathrm{L}$ increase & 0.987 & 0.001 & 0.979 to 0.994 \\
Molybdenum & Every $1 \mathrm{ng} / \mathrm{mL}$ increase & 1.005 & 0.002 & 1.002 to 1.009 \\
Creatine kinase & 27 to $86 \mathrm{U} / \mathrm{L}$ & Referent & & \\
& 87 to $132 \mathrm{U} / \mathrm{L}$ & 1.073 & 0.467 & 0.089 to 1.302 \\
& 134 to $195 \mathrm{U} / \mathrm{L}$ & 0.779 & 0.015 & 0.637 to 0.953 \\
Haptoglobin & 196 to $877 \mathrm{U} / \mathrm{L}$ & 0.768 & 0.01 & 0.628 to 0.940 \\
& 0.11 to $0.15 \mathrm{~g} / \mathrm{L}$ & Referent & & \\
& 0.16 to $0.16 \mathrm{~g} / \mathrm{L}$ & 1.130 & 0.254 & 0.916 to 1.393 \\
Constant & 0.17 to $0.19 \mathrm{~g} / \mathrm{L}$ & 1.348 & 0.002 & 1.117 to 1.628 \\
& 0.2 to $2.11 \mathrm{~g} / \mathrm{L}$ & 1.305 & 0.008 & 1.073 to 1.589 \\
& & 0.058 & & \\
\hline
\end{tabular}

\section{Mortality Model}

Navel score, fecal score, rectal temperature, serum total protein, treatment with group antibiotic treatment, weight at arrival, cholesterol, haptoglobin, and $\operatorname{IgG}$ were associated with mortality in the univariable analysis. In the final model, increased cholesterol and IgG were associated with a decreased hazard of dying (Table 6). Harrell's C concordance statistic of this model was 0.62 . In a second Cox proportional hazard model, weight upon arrival was included. Higher weight was associated with a decreased hazard of dying, while cholesterol and IgG tended to be associated with a decreased hazard of dying (Table 7). Harrel's C concordance statistic when weight on arrival was included in the model was 0.65 , demonstrating that the model including weight upon arrival and blood parameters could correctly order survival times for pairs of calves $65 \%$ of the time. This suggested that the predictive ability of this model was fair. Cut points were generated using the Youden Index to determine the optimal cut point for weight, IgG, and cholesterol to predict mortality (Table 8).

\section{DISCUSSION}

The aim of this study was to identify biomarkers measured upon arrival at a veal facility that were associated with ADG, morbidity, and mortality. Several metabolic indicators, as well as weight upon arrival, were associated with morbidity, mortality, and ADG. However, there are several limitations to consider when interpreting the results of this study. As stated in Scott et al. (2019), the producer was very selective about which calves were purchased to enter this facility, and visually less healthy calves were avoided. This control over the purchase of calves is not common among veal producers in Canada and may have introduced selec- tion bias, which could limit the external validity of this study. We also relied on treatment and mortality records collected from the farm that may have been subject to errors. In addition to potential data recording errors, studies have shown that farm personnel may not always accurately classify calves as sick or healthy. Virtala et al. (1996b) reported that caregivers overdiagnosed diarrhea compared with veterinary diagnoses based on clinical signs. Similarly, Svensson et al. (2003) reported farmers underdiagnosing respiratory disease compared with veterinarians. However, using farm treatment and mortality records for analysis reflected the current reality of the industry where personnel use clinical scoring to evaluate the calves to make treatment decisions. Furthermore, source and age of calves upon arrival to the veal facility have been reportedly associated with morbidity and mortality throughout the growing period at the veal facility (Knowles, 1995; Winder et al., 2016); however, the source of the calves was not captured during data collection, which could have affected our results. Moreover, due to poor record keeping at the finishing facility, morbidity, mortality, and ADG could only be recorded during the starter phase, which poses the highest risk of morbidity and mortality (Pardon et al., 2012). Therefore, the biomark-

Table 5. Cut points determined by Youden's index to maximize sensitivity (Se) and specificity (Sp) for metabolic indicators measured at arrival for predicting morbidity in 992 calves at a grain-fed veal facility in southwestern Ontario

\begin{tabular}{lcccc}
\hline Variable & $\begin{array}{c}\text { Cut } \\
\text { point }\end{array}$ & Se & Sp & AUC $^{1}$ \\
\hline IgG (g/L) & 17.85 & 0.55 & 0.38 & 0.47 \\
Weight (kg) & 46.04 & 0.55 & 0.46 & 0.50 \\
Creatine kinase (U/L) & 150.5 & 0.40 & 0.52 & 0.46 \\
Haptoglobin (g/L) & 0.155 & 0.58 & 0.55 & 0.57 \\
Molybdenum (ng/mL) & 11.5 & 0.49 & 0.62 & 0.56 \\
\hline
\end{tabular}

${ }^{1} \mathrm{AUC}=$ area under the curve. 
Table 6. Results from a Cox proportional hazard model identifying metabolic indicators associated with mortality during the 78-d period of observation in 992 calves when measured on arrival at a grain-fed veal facility in southwestern Ontario

\begin{tabular}{llccc}
\hline Variable & Description & $\begin{array}{c}\text { Hazard } \\
\text { ratio }\end{array}$ & $P$-value & $95 \%$ CI \\
\hline IgG $(\mathrm{g} / \mathrm{L})$ & Every $1 \mathrm{~g} / \mathrm{L}$ increase & 0.971 & 0.029 & 0.946 to 0.997 \\
Cholesterol $(\mathrm{mmol} / \mathrm{L})$ & Every $1 \mathrm{mmol} / \mathrm{L}$ increase & 0.572 & 0.011 & 0.372 to 0.879 \\
\hline
\end{tabular}

ers in the present study are associated with morbidity, mortality, and ADG during early veal rearing, and not necessarily indicative of overall calf health and performance throughout the entire growing period.

Calves arriving with higher concentrations of cholesterol had an increased ADG and a decreased hazard of mortality. These results agree with Renaud et al. (2018), who identified cholesterol as a marker for mortality in calves arriving at a milk-fed veal facility. The biological reasoning for this relationship remains unclear; however, it could be due to several different factors. Cholesterol plays a critical role in mediating postnatal growth and development by influencing intestinal signaling and promoting of intestinal lactase activity, which may explain its role in increasing ADG (Ontsouka et al., 2016). Higher cholesterol levels may also represent older calves, as cholesterol increases with age, and calves transported at an older age could be at a lower risk of mortality (Knowles, 1995; Piccione et al., 2010). Cholesterol may also be a marker of colostrum intake because cholesterol concentration is much higher in colostrum than in milk (Ontsouka et al., 2016). Additionally, cholesterol deficiency haplotype results in low levels of cholesterol and causes emaciation, growth, retardation, and diarrhea, and consequently increases levels of mortality (Kipp et al., 2016; Otter and Hateley, 2017). This haplotype may be common in Canada and could explain the association between cholesterol concentrations and calf health (Kipp et al., 2016). Cholesterol concentrations in calves can be affected by many elements; therefore greater understanding of the mechanisms by which cholesterol influences calf health and growth is needed.

Having higher IgG levels was associated with an increased ADG and a reduced morbidity and mortality in our study. Calves are born agammaglobulinemic and depend almost entirely on the absorption of maternal immunoglobulins from colostrum after birth (Godden, 2008). It is well understood that successful passive transfer of $\operatorname{IgG}$ is imperative to calf health. A recent meta-analysis further highlighted the importance of $\operatorname{IgG}$, as a dairy or beef calf that has failed transfer of passive immunity of IgG is 2 times as likely to die, 1.8 times as likely to be treated for respiratory disease, and 1.5 times as likely to be treated for diarrhea when compared with a calf with successful passive transfer of IgG (Raboisson et al., 2016). Historically, failed transfer of passive immunity has been defined as serum IgG levels < $10 \mathrm{~g} / \mathrm{L}$ (Gay, 1983; Weaver et al., 2000). However, in this study, the optimal cut points for serum IgG were found to be $17.85 \mathrm{~g} / \mathrm{L}$ and $19.85 \mathrm{~g} / \mathrm{L}$ for predicting morbidity and mortality, respectively, aligning with more recent studies demonstrating that the target cut point for successful passive transfer of IgG requires reconsideration (Urie et al., 2018). In fact, a recent consensus recommendation from researchers in the United States proposed 4 serum IgG categories where calves are classified as excellent $(>25.0 \mathrm{~g} / \mathrm{L})$, good $(18.0$ to $24.9 \mathrm{~g} / \mathrm{L})$, fair $(10.0$ to $17.9 \mathrm{~g} / \mathrm{L})$, and poor $(<10$ $\mathrm{g} / \mathrm{L}$ ), agreeing with the current study (Lombard et al., 2020 ). Veal producers rely entirely on dairy producers to ensure adequate passive transfer at the dairy farm of origin, yet some dairy producers may provide differential treatment to male calves. Recent studies have documented that male calves are not always fed colostrum, fed lower volumes of colostrum, fed more contaminated colostrum, and receive differing levels of nutrition when compared with female calves (Fecteau et al., 2002; Renaud et al., 2017; Shivley et al., 2019). Additionally, Renaud et al. (2020) found that male

Table 7. Results from a Cox proportional hazard model identifying metabolic indicators and weight associated with mortality during the 78-d period of observation in 992 calves when measured on arrival at a grain-fed veal facility in southwestern Ontario

\begin{tabular}{llccc}
\hline Variable & Description & $\begin{array}{c}\text { Hazard } \\
\text { ratio }\end{array}$ & $P$-value & $95 \%$ CI \\
\hline Weight $(\mathrm{kg})$ & Every 1-kg increase & 0.925 & $<0.01$ & 0.876 to 0.976 \\
$\mathrm{IgG}(\mathrm{g} / \mathrm{L})$ & Every $1 \mathrm{~g} / \mathrm{L}$ increase & 0.976 & 0.064 & 0.950 to 1.001 \\
Cholesterol $(\mathrm{mmol} / \mathrm{L})$ & Every $1 \mathrm{mmol} / \mathrm{L}$ increase & 0.643 & 0.052 & 0.4111 to 1.005 \\
\hline
\end{tabular}


Table 8. Cut points determined by Youden's index to maximize sensitivity (Se) and specificity (Sp) for metabolic indicators measured at arrival for predicting mortality in 992 calves at a grain-fed veal facility in southwestern Ontario

\begin{tabular}{lcccc}
\hline Variable & $\begin{array}{c}\text { Cut } \\
\text { point }\end{array}$ & Se & Sp & AUC $^{1}$ \\
\hline IgG $(\mathrm{g} / \mathrm{L})$ & 19.85 & 0.44 & 0.52 & 0.48 \\
Weight $(\mathrm{kg})$ & 44.23 & 0.62 & 0.29 & 0.45 \\
Cholesterol $(\mathrm{mmol} / \mathrm{L})$ & 1.975 & 0.38 & 0.56 & 0.47 \\
\hline
\end{tabular}

${ }^{1} \mathrm{AUC}=$ area under the curve.

calves have lower concentrations of serum total protein than female dairy calves and were more likely to be fed pooled colostrum. The current study further highlights the importance of dairy producers' care of male calves before arrival to the veal facility, and a focus needs to be placed on determining how to improve the care of male calves on some dairy farms.

Our study found higher BW at arrival to be positively associated with ADG and decreased hazard of morbidity and mortality during the $78 \mathrm{~d}$ under observation. Other studies have shown a similar relationship, in which lower weight at arrival was associated with higher morbidity and mortality (Brscic et al., 2012; Winder et al., 2016). Body weight upon arrival has been considered the most reliable predictor for future disease at the veal farm, but it can be highly influenced by a variety of factors (Marcato et al., 2018). Some suggested factors include birth weight, age at arrival, and nutrition; however, the effect of these factors on calf weight upon arrival to the veal facility has not been elucidated. Despite the inability to disentangle the underlying relationship between these factors and future calf health in the present study, measuring weight upon arrival may be more practical than evaluating biomarkers and more consistent than clinically assessing calves to detect high-risk calves. Future research should investigate the effects of these factors on weight measured upon arrival to better understand its predictive ability of future calf health.

Existing literature has described CK as an indicator of tissue damage, poor muscular tissue reperfusion, hypoxia, and fatigue (Tadich et al., 2005). Creatine kinase is notably increased in calves arriving to a veal farm compared with pretransport values, suggesting changes in plasma enzymes such as CK may serve as indicators of tissue damage in diseased animals (Boyd, 1983; Jongman and Butler, 2014). Increased concentrations of CK posttransport have also been associated with stocking density and bedding provided during transportation, with calves transported with the least space provided experiencing elevated CK levels, and calves transported with straw bedding having lower CK concentrations (Jongman and Butler, 2014). These factors were not recorded in this study, and thus these relationships could not be assessed. However, in the present study, increased levels of CK were associated with increased ADG and decreased hazard of morbidity. Information on the relationship of this enzyme and future disease is scarce in calves; however, Marcato et al. (2018) speculated that higher levels of these enzymes could be positive indicators of restored homeostasis after transport or other challenges. When calves are stressed, they may attempt to restore homeostasis by adjusting physiological processes, including enhancing production of CK because CK plays a significant role in energy homeostasis of tissue cells (Teixeira and Borges, 2012; Marcato et al., 2018). In humans, an increase in biomarkers associated with muscle degradation have also been associated with muscle hypertrophy; therefore, calves with better growth may also experience a greater turnover of muscle mass and result in elevated concentrations of CK (Léger et al., 2006). This could explain the positive relationship of $\mathrm{CK}$ with $\mathrm{ADG}$ and decreased hazard of morbidity that was found.

Not surprisingly, increased haptoglobin concentration was associated with an increased hazard of morbidity, but had a poor discriminative ability to identify individual calves at risk for disease during the $78 \mathrm{~d}$ at this facility. This acute phase protein (APP) increases in calves in response to stressors such as weaning, transportation, and bovine respiratory disease (Lomborg et al., 2008; Kim et al., 2011; Orro et al., 2011). Elevation in APP levels has been reported to be much greater in diseased calves than in healthy calves, highlighting its role in immune system modulation and suggesting its utility for the early diagnosis of disease (Gånheim et al., 2003; Yun et al., 2014). In addition, it has also been shown that veal calves with increased APP concentrations experience a decrease in ADG (Pardon et al., 2015). Murray et al. (2014) identified a cut point of $>0.13 \mathrm{~g} / \mathrm{L}$ (Se 27\%, Sp 80\%) in the first week of life to be associated with increased odds of future treatment of bovine respiratory disease, treatment for other diseases, and death. We identified a cut point of $>0.16 \mathrm{~g} / \mathrm{L}$ (Se $58 \%$, Sp 55\%), to be predictive of diarrhea and respiratory disease during the 78 -d period of observation. This slight increase in cut point identified in our study may be due to sex differences or other management factors, as the previous study was conducted in heifer calves at a dairy farm. Furthermore, our attempts to determine the optimal cutoff point to maximize sensitivity and specificity for predicting morbidity and mortality yielded poor results, suggesting that this biomarker alone is not enough for predicting future disease risk in calves at arrival to a veal facility.

Trace minerals are required for the functioning of enzymes involved in the antioxidant defense system, 
which may also affect immune cells (Spears, 2000). In this study, as the concentration of zinc increased, ADG decreased. However, for molybdenum, as levels increased, so did the hazard of morbidity. It is possible that excess zinc or molybdenum may cause a borderline deficiency of other essential nutrients by interfering with their utilization or metabolism, thereby negatively affecting calf health (Miller, 1970). Elevated concentrations of iron and copper were positively associated with ADG. Compared with adult cows, calves require higher levels of iron to meet growth requirements, and iron deficiency can cause anemia and a weakened immune system. (van Ravenswaay et al., 2001; Cui et al., 2017). Our results further demonstrated iron's important role in calf health. Teixeira et al. (2014) showed a beneficial effect of an injectable trace mineral supplementation containing zinc, manganese, selenium, and copper on reducing incidence of diarrhea and odds of combined incidence of pneumonia and otitis in Holstein heifer calves when compared with calves that did not receive the trace mineral supplement. This beneficial effect did not translate to improved ADG or reduced mortality. In a retrospective study of dairy and beef herds evaluating the relationship between trace-element status of cows and the health of their calves, Enjalbert et al. (2006) demonstrated that trace mineral concentrations in calves are also influenced by the trace mineral status of dams, and inadequate trace mineral nutrition is a risk factor for poor health in calves. The serum concentrations of trace minerals may also be influenced by the acute phase response due to binding by other proteins. For example, ceruloplasmin is the major copper binding protein that increases during injury or infection (Taggart et al., 1990). With many factors influencing trace mineral status in calves, utilization of any single mineral individually would prove challenging without further understanding of the underlying associations between them and calf health.

\section{CONCLUSIONS}

Reliable biomarkers could be used as tools for predicting future calf health and productivity when measured upon arrival at a veal facility. Identifying calves at high risk of morbidity and mortality or reduced ADG would allow producers to intervene earlier and optimize calf health and welfare during the growing period. Higher weight on arrival, CK, cholesterol, IgG, iron, and copper were positively associated with calf health, whereas elevated zinc, haptoglobin, and molybdenum were negatively associated with calf health. Before future use can be plausible, it would be beneficial to better understand the underlying mechanisms of these biomarkers and their practical application.

\section{ACKNOWLEDGMENTS}

The authors acknowledge the veal producer for allowing us to complete this work at their facility (Drayton, ON, Canada). The first author was supported by Veal Farmers of Ontario (Guelph, Ontario, Canada) and the Ontario Ministry of Agriculture, Food, and Rural Affairs (Guelph, Ontario, Canada). The authors declare no conflict of interest.

\section{REFERENCES}

Bateman, K. G., S. W. Martin, P. E. Shewen, and P. I. Menzies. 1990. An evaluation of antimicrobial therapy for undifferentiated bovine respiratory disease. Can. Vet. J. 31:689-696.

Bernardini, D., G. Gerardi, A. Peli, L. Nanni Costa, M. Amadori, and S. Segato. 2012. The effects of different environmental conditions on thermoregulation and clinical and hematological variables in long-distance road-transported calves. J. Anim. Sci. 90:1183-1191. https://doi.org/10.2527/jas.2011-4113.

Boyd, J. W. 1983. The mechanisms relating to increases in plasma enzymes and isoenzymes in diseases of animals. Vet. Clin. Pathol. 12:9-24. https://doi.org/10.1111/j.1939-165X.1983.tb00609.x.

Brscic, M., H. Leruste, L. F. Heutinck, E. A. Bokkers, M. WolthuisFillerup, N. Stockhofe, F. Gottardo, B. J. Lensink, G. Cozzi, and C. G. Van Reenen. 2012. Prevalence of respiratory disorders in veal calves and potential risk factors. J. Dairy Sci. 95:2753-2764. https://doi.org/10.3168/jds.2011-4699.

Buczinski, S., R. D. Rademacher, H. M. Tripp, M. Edmonds, E. G. Johnson, and S. Dufour. 2015. Assessment of L-lactatemia as a predictor of respiratory disease recognition and severity in feedlot steers. Prev. Vet. Med. 118:306-318. https://doi.org/10.1016/j .prevetmed.2014.12.003.

Chelack, B. J., P. S. Morley, and D. M. Haines. 1993. Evaluation of methods for dehydration of bovine colostrum for total replacement of normal colostrum in calves. Can. Vet. J. 34:407-412.

Cui, K., Y. Tu, Y. C. Wang, N. F. Zhang, T. Ma, and Q. Y. Diao. 2017. Effects of a limited period of iron supplementation on the growth performance and meat colour of dairy bull calves for veal production. Anim. Prod. Sci. 57:778-784. https://doi.org/10 .1071/AN15388.

Dohoo, I., W. Martin, and H. Stryhn. 2010. Model-building strategies. Pages 365-394 in Veterinary Epidemiological Research. 2nd ed. VER Inc., Charlottetown, Canada.

Enjalbert, F., P. Lebreton, and O. Salat. 2006. Effects of copper, zinc and selenium status on performance and health in commercial dairy and beef herds: Retrospective study. J. Anim. Physiol Anim. Nutr. (Berl.) 90:459-466. https://doi.org/10.1111/j.1439 $-0396.2006 .00627 . x$.

Fecteau, G., P. Baillargeon, R. Higgins, J. Paré, and M. Fortin. 2002. Bacterial contamination of colostrum fed to newborn calves in Québec dairy herds. Can. Vet. J. 43:523-527.

Gånheim, C., C. Hulten, U. Carlsson, H. Kindahl, R. Niskanen, and K. P. Waller. 2003. The acute phase response in calves experimentally infected with bovine viral diarrhoea virus and/or Mannheimia haemolytica. Zoonoses Public Health 50:183-190. https://doi.org/10 .1046/j.1439-0450.2003.00658.x.

Godden, S. 2008. Colostrum management for dairy calves. Vet. Clin. North Am. Food Anim. Pract. 24:19-39. https://doi.org/10.1016/ j.cvfa.2007.10.005.

Hulbert, L. E., and S. J. Moisa. 2016. Stress, immunity, and the management of calves. J. Dairy Sci. 99:3199-3216. https://doi.org/10 $.3168 /$ jds.2015-10198.

Jongman, E. C., and K. L. Butler. 2014. The effect of age, stocking density and flooring during transport on welfare of young dairy calves in Australia. Animals (Basel) 4:184-199. https://doi.org/ 10.3390/ani4020184. 
Kim, M. H., J. Y. Yang, S. D. Upadhaya, H. J. Lee, C. H. Yun, and J. K. Ha. 2011. The stress of weaning influences serum levels of acute-phase proteins, iron-binding proteins, inflammatory cytokines, cortisol and leukocyte subsets in Holstein calves. J. Vet. Sci. 12:151-157. https://doi.org/10.4142/jvs.2011.12.2.151.

Kipp, S., D. Segelke, S. Schierenbeck, F. Reinhardt, R. Reents, C. Wurmser, H. Pausch, R. Fries, G. Thaller, J. Tetens, J. Pott, D. Haas, B. Raddatz, M. Hewicker-Trautwein, I. Proios, M. Schmicke, and W. Grünberg. 2016. Identification of a haplotype associated with cholesterol deficiency and increased juvenile mortality in Holstein cattle. J. Dairy Sci. 99:8915-8931. https://doi.org/10.3168/ jds.2016-11118.

Knowles, T. G. 1995. A review of post transport mortality among younger calves. Vet. Rec. 137:406-407. https://doi.org/10.1136/ vr.137.16.406.

Knowles, T. G., P. Warriss, S. Brown, J. Edwards, P. Watkins, and A. Phillips. 1997. Effects on calves less than one month old of feeding or not feeding them during road transport of up to 24 hours. Vet. Rec. 140:116-124. https://doi.org/10.1136/vr.140.5.116.

Léger, B., R. Cartoni, M. Praz, S. Lamon, O. Dériaz, A. Crettenand, C. Gobelet, P. Rohmer, M. Konzelmann, F. Luthi, and A. P. Russell. 2006. Akt signalling through GSK-33, mTOR and Foxo1 is involved in human skeletal muscle hypertrophy and atrophy. J. Physiol. 576:923-933. https://doi.org/10.1113/jphysiol.2006 .116715 .

Lombard, J., N. Urie, F. Garry, S. Godden, J. Quigley, T. Earleywine, S. McGuirk, D. Moore, M. Branan, M. Chamorro, G. Smith, C. Shivley, D. Catherman, D. Haines, A. J. Heinrichs, R. James, J. Maas, and K. Sterner. 2020. Consensus recommendations on calf- and herd-level passive immunity in dairy calves in the United States. J. Dairy Sci. 103:7611-7624. https://doi.org/10.3168/jds .2019-17955.

Lomborg, S. R., L. R. Nielsen, P. M. Heegaard, and S. Jacobsen. 2008. Acute phase proteins in cattle after exposure to complex stress. Vet. Res. Commun. 32:575-582. https://doi.org/10.1007/s11259 -008-9057-7.

Marcato, F., H. van den Brand, B. Kemp, and K. van Reenen. 2018. Evaluating potential biomarkers of health and performance in veal calves. Front. Vet. Sci. 5:133. https://doi.org/10.3389/fvets.2018 .00133 .

Miller, W. J. 1970. Zinc nutrition of cattle: A review. J. Dairy Sci. 53:1123-1135. https://doi.org/10.3168/jds.S0022-0302(70)86355 $-\mathrm{X}$.

Montgomery, S. P., J. J. Sindt, M. A. Greenquist, W. F. Miller, J. N. Pike, E. R. Loe, M. J. Sulpizio, and J. S. Drouillard. 2009. Plasma metabolites of receiving heifers and the relationship between apparent bovine respiratory disease, body weight gain, and carcass characteristics. J. Anim. Sci. 87:328-333. https://doi.org/10.2527/ jas. 2008-0969.

Murray, C. F., M. Windeyer, T. Duffield, D. Haley, D. Pearl, K. Waalderbos, and K. Leslie. 2014. Associations of serum haptoglobin in newborn dairy calves with health, growth, and mortality up to 4 months of age. J. Dairy Sci. 97:7844-7855. https://doi.org/10 3168/jds.2014-8465.

O'Connor, A. M., J. M. Sargeant, I. R. Dohoo, H. N. Erb, M. Cevallos, M. Egger, A. K. Ersbøll, S. W. Martin, L. R. Nielsen, D. L. Pearl, D. U. Pfeiffer, J. Sanchez, M. E. Torrence, H. Vigre, C. Waldner, and M. P. Ward. 2016. Explanation and elaboration document for the STROBE-Vet statement: Strengthening the reporting of observational studies in epidemiology-Veterinary extension. J. Vet. Intern. Med. 30:1896-1928. https://doi.org/10.1111/jvim.14592.

Ontsouka, E. C., C. Albrecht, and R. M. Bruckmaier. 2016. Invited review: Growth-promoting effects of colostrum in calves based on interaction with intestinal cell surface receptors and receptor-like transporters. J. Dairy Sci. 99:4111-4123. https://doi.org/10.3168/ jds.2015-9741.

Orro, T., T. Pohjanvirta, U. Rikula, A. Huovilainen, S. Alasuutari, L. Sihvonen, S. Pelkonen, and T. Soveri. 2011. Acute phase protein changes in calves during an outbreak of respiratory disease caused by bovine respiratory syncytial virus. Comp. Immunol. Microbiol. Infect. Dis. 34:23-29. https://doi.org/10.1016/j.cimid.2009.10.005.
Otter, A., and G. Hateley. 2017. Blood cholesterol concentrations in dairy calves. Vet. Rec. 180:52. https://doi.org/10.1136/vr.j122.

Pardon, B., J. Alliët, R. Boone, S. Roelandt, B. Valgaeren, and P. Deprez. 2015. Prediction of respiratory disease and diarrhea in veal calves based on immunoglobulin levels and the serostatus for respiratory pathogens measured at arrival. Prev. Vet. Med. 120:169-176. https://doi.org/10.1016/j.prevetmed.2015.04.009.

Pardon, B., K. De Bleecker, M. Hostens, J. Callens, J. Dewulf, and P. Deprez. 2012. Longitudinal study on morbidity and mortality in white veal calves in Belgium. BMC Vet. Res. 8:26. https://doi.org/ 10.1186/1746-6148-8-26.

Paré, J., M. C. Thurmond, I. A. Gardner, and J. P. Picanso. 1993. Effect of birthweight, total protein, serum IgG and packed cell volume on risk of neonatal diarrhea in calves on two California dairies. Can. J. Vet. Res. 57:241-246.

Piccione, G., S. Casella, P. Pennisi, C. Giannetto, A. Costa, and G. Caola. 2010. Monitoring of physiological and blood parameters during perinatal and neonatal period in calves. Arq. Bras. Med. Vet. Zootec. 62:1-12. https://doi.org/10.1590/S0102 -09352010000100001.

Pletcher, M. J., and M. Pignone. 2011. Evaluating the clinical utility of a biomarker: A review of methods for estimating health impact. Circulation 123:1116-1124. https://doi.org/10.1161/ CIRCULATIONAHA.110.943860.

Raboisson, D., P. Trillat, and C. Cahuzac. 2016. Failure of passive immune transfer in calves: A meta-analysis on the consequences and assessment of the economic impact. PLoS One 11:e0150452. https: //doi.org/10.1371/journal.pone.0150452.

Renaud, D. L., T. Duffield, S. LeBlanc, D. Haley, and D. Kelton. 2017. Management practices for male calves on Canadian dairy farms. J. Dairy Sci. 100:6862-6871. https://doi.org/10.3168/jds.2017-12750.

Renaud, D. L., T. F. Duffield, S. J. LeBlanc, D. B. Haley, and D. F. Kelton. 2018. Clinical and metabolic indicators associated with early mortality at a milk-fed veal facility: A prospective case-control study. J. Dairy Sci. 101:2669-2678. https://doi.org/10.3168/ jds.2017-14042.

Renaud, D. L., K. M. Waalderbos, L. Beavers, T. F. Duffield, K. E. Leslie, and M. C. Windeyer. 2020. Risk factors associated with failed transfer of passive immunity in male and female dairy calves: A 2008 retrospective cross-sectional study. J. Dairy Sci. 103:35213528. https://doi.org/10.3168/jds.2019-17397.

Scott, K., D. F. Kelton, T. F. Duffield, and D. L. Renaud. 2019. Risk factors identified on arrival associated with morbidity and mortality at a grain-fed veal facility: A prospective, single-cohort study. J. Dairy Sci. 102:9224-9235. https://doi.org/10.3168/jds.2019-16829.

Shivley, C. B., J. E. Lombard, N. J. Urie, D. M. Weary, and M. A. G. von Keyserlingk. 2019. Management of preweaned bull calves on dairy operations in the United States. J. Dairy Sci. 102:4489-4497. https://doi.org/10.3168/jds.2018-15100.

Skinner, J. G., R. Brown, and L. Roberts. 1991. Bovine haptoglobin response in clinically defined field conditions. Vet. Rec. 128:147149. https://doi.org/10.1136/vr.128.7.147.

Spears, J. W. 2000. Micronutrients and immune function in cattle. Proc. Nutr. Soc. 59:587-594. https://doi.org/10.1017/ S0029665100000835.

Svensson, C., K. Lundborg, U. Emanuelson, and S. Olsson. 2003. Morbidity in Swedish dairy calves from birth to 90 days of age and individual calf-level risk factors for infectious diseases. Prev. Vet. Med. 58:179-197. https://doi.org/10.1016/S0167-5877(03)00046 $-1$.

Tadich, N., C. Gallo, H. Bustamante, M. Schwerter, and G. van Schaik. 2005. Effects of transport and lairage time on some blood constituents of Friesian-cross steers in Chile. Livest. Prod. Sci. 93:223-233. https://doi.org/10.1016/j.livprodsci.2004.10.004.

Taggart, D. P., W. D. Fraser, A. Shenkin, D. J. Wheatley, and G. S. Fell. 1990. The effects of intraoperative hypothermia and cardiopulmonary bypass on trace metals and their protein binding ratios. Eur. J. Cardiothorac. Surg. 4:587-594. https://doi.org/10.1016/ 1010-7940(90)90017-T.

Teixeira, A. G. V., F. S. Lima, M. L. S. Bicalho, A. Kussler, S. F. Lima, M. J. Felippe, and R. C. Bicalho. 2014. Effect of an inject- 
able trace mineral supplement containing selenium, copper, zinc, and manganese on immunity, health, and growth of dairy calves. J. Dairy Sci. 97:4216-4226. https://doi.org/10.3168/jds.2013-7625.

Teixeira, A. M., and G. F. Borges. 2012. Creatine kinase: Structure and function. Braz. J. Biomot. 6:53-65.

Thompson, P. N., A. Stone, and W. A. Schultheiss. 2006. Use of treatment records and lung lesion scoring to estimate the effect of respiratory disease on growth during early and late finishing period in South African feedlot cattle. J. Anim. Sci. 84:488-498. https:// doi.org/10.2527/2006.842488x.

Urie, N. J., J. E. Lombard, C. B. Shivley, C. A. Kopral, A. E. Adams, T. J. Earleywine, J. D. Olson, and F. B. Garry. 2018. Preweaned heifer management on US dairy operations: Part I. Descriptive characteristics of preweaned heifer raising practices. J. Dairy Sci. 101:9168-9184. https://doi.org/10.3168/jds.2017-14010.

Van de Water, G., F. Verjans, and R. Geers. 2003. The effect of short distance transport under commercial conditions on the physiology of slaughter calves; $\mathrm{pH}$ and colour profiles of veal. Livest. Prod. Sci. 82:171-179. https://doi.org/10.1016/S0301-6226(03)00010-1.

van Ravenswaay, R. O., P. R. Henry, and C. B. Ammerman. 2001 Effects of time and dietary iron on tissue iron concentration as an estimate of relative bioavailability of supplemental iron sources for ruminants. Anim. Feed Sci. Technol. 90:185-198. https://doi.org/ 10.1016/S0377-8401(01)00208-5.

Virtala, A. M., G. D. Mechnor, Y. T. Gröhn, and H. N. Erb. 1996b. Morbidity from nonrespiratory diseases and mortality in dairy heifers during the first three months of life. J. Am. Vet. Med. Assoc. 208:2043-2046.
Virtala, A. M., G. D. Mechor, Y. T. Gröhn, and H. N. Erb. 1996a. The effect of calfhood diseases on growth of female dairy calves during the first 3 months of life in New York State. J. Dairy Sci. 79:10401049. https://doi.org/10.3168/jds.S0022-0302(96)76457-3.

Weaver, D. M., J. W. Tyler, D. C. VanMetre, D. E. Hostetler, and G. M. Barrington. 2000. Passive transfer of colostral immunoglobulins in calves. J. Vet. Intern. Med. 14:569-577. https://doi.org/10 $.1111 /$ j.1939-1676.2000.tb02278.x.

Winder, C. B., D. F. Kelton, and T. F. Duffield. 2016. Mortality risk factors for calves entering a multi-location white veal farm in Ontario, Canada. J. Dairy Sci. 99:10174-10181. https://doi.org/10 $.3168 /$ jds.2016-11345.

Youden, W. J. 1950. Index for rating diagnostic tests. Cancer 3:32-35. https://doi.org/10.1002/1097-0142(1950)3:1<32::AIDCNCR2820030106>3.0.CO;2-3.

Yun, C., P. Wynn, and J. Ha. 2014. Stress, acute phase proteins and immune modulation in calves. Anim. Prod. Sci. 54:1561-1568. https://doi.org/10.1071/AN14441.

\section{ORCIDS}

H. M. Goetz (1) https://orcid.org/0000-0001-9838-2921

D. F. Kelton () https://orcid.org/0000-0001-9606-7602

J. H. C. Costa ๑ https://orcid.org/0000-0001-9311-4741

C. B. Winder @ https://orcid.org/0000-0002-7314-3657

D. L. Renaud ( ) https://orcid.org/0000-0002-3439-3987 